\title{
Ohran taloudellinen fosforilannoitus vuokrapellolla
}

\author{
Sami Myyrä, Kyösti Pietola \\ MTT Taloustutkimus, Luutnantintie 13,00410 Helsinki, sami.myyra@mtt.fi, kyosti.pietola@mtt.fi
}

\begin{abstract}
Johdanto
Vuokrapeltoja viljelevien viljelijöiden voi olla vaikea löytää taloudellisia kannusteita pellon kasvukunnosta huolehtimiseen. Maamme pelloista $30-40 \%$ on vuokraviljelyssä. Tässä tutkimuksessa käytettävällä dynaamisen ohjelmoinnin menetelmällä osoitetaan esimerkkilaskelmien avulla, miten vuokraviljelijän kohtaama epävarmuus vuokraviljelmän hallintaoikeuden jatkumisesta vaikuttaa taloudellisin perustein tehtävään fosforilannoitukseen. Esimerkkilaskelmien tavoitteena ei ole muodostaa fosforilannoitussuosituksia, vaan niillä kuvataan vuokraviljelijän taloudellisesti rationaalisia lannoitusvalintoja. Pidempiaikaisista perusparannuksista kalkitus ja ojitus voidaan mallintaa samaan tapaan, joten nyt tarkastelun kohteena oleva fosforilannoitusmalli antaa kuvan epävarmuuden aiheuttamista vaikutuksista vuokraviljelijän toimintaan.

Tässä tarkastelussa on keskeistä ja aikaisemmista tutkimuksista poikkeavaa se, että fosforilannoituksen (helppoliukoisen fosforin varannosta riippuva) suora vaikutus satoon ja maan helppoliukoisen fosforin varannon vaikutus satoon on erotettu toisistaan ja niitä tarkastellaan erillisillä responssifunktioilla. Näiden kahden perusteella muodostuu kokonaissato. Käytetyllä menettelytavalla on tuotu uusi lähestymistapa ongelmiin, jotka liittyvät lannoitteen siirtymäfunktion määrittelyyn pitemmillä, yli viiden vuoden suunnittelujänteillä (Kennedy 1986).

Vuokraviljelmän fosforilannoitusmalli on karkea yleistys todellisuudesta. Fosfori esiintyy maassa useissa eri olomuodoissa. Näissä eri olomuodoissa olevan fosforin oletetaan tässä tarkastelussa summautuvan yhdeksi varannoksi, jota kuvataan viljavuusanalyysillä havaittavalla helppoliukoisella fosforilla. Toinen keskeinen yleistys on se, että fosforilannoituksen ja kalkituksen taloutta ei kytketä yhteen, vaikka niiden tiedetään liittyvän toisiinsa. Kolmantena karkeana yleistyksenä on oletus siitä, ettei vuokraviljelijän pellon kasvukuntoon kohdistamilla toimilla ole vaikutusta vuokrasopimuksen uusiutumisen todennäköisyyteen. Käytännössä hyvän viljelijän maineen saanut viljelijä saattaa saada helpommin vuokrapeltoja.
\end{abstract}

\section{Aineisto ja menetelmä}

Käytetty normatiivinen tutkimusote perustuu dynaamiseen ohjelmointiin ja sen sovellutuksiin taloudellisen lannoituksen laskennassa (Kennedy 1986). Fosforilannoituksen ja maassa olevan helppoliukoisen fosforin vaikutuksia ohran satoon sekä lannoitteena annetun fosforin maahan pidättymistä kuvaavat normit perustuvat MTT:ssä tehtyihin tutkimuksiin (Saarela ym. 1995). Mallin perusoletuksilla omistajaviljelijän pitkän aikavälin taloudellinen fosforilannoitus asettuu tasolle $17 \mathrm{~kg} / \mathrm{ha}$, mikä pitää maan helppoliukoisen fosforivarannon tyydyttävässä viljavuusluokassa.

Pellon hallinta-ajan vaikutus optimaaliseen fosforilannoituksen tasoon selvitettiin käyttäen seuraavia lähtötietoja ja -oletuksia:

- Lannoitefosforin hinta on $1220 € /$ tonni. Fosforin hinnan laskenta perustuu vakioituun $90 \mathrm{~kg} / \mathrm{ha}$ typpilannoitukseen ja fosforilannoituksen variaatioihin eri lannoitteilla (Myyrä ym. 2003). Ohran hintana käytetään $110 € /$ tonni.

- Lannoitefosforin käyttö rajoittamaton, ei esim. ympäristöohjelmien rajoituksia.

- Muu lannoitus / viljelytoimet optimaalisia biologisen satomaksimin saavuttamiseksi. Mallin satoennusteet (esim. pitkä aikaväli, ei epävarmuutta $3380 \mathrm{~kg} / \mathrm{ha}$ ) vastaavat käytännön viljelyssä saatuja keskisatoja koko maassa, $3290 \mathrm{~kg} / \mathrm{ha}$ (2001) ja $3330 \mathrm{~kg} / \mathrm{ha}$ (2002) (Maataloustilastollinen vuosikirja 2002).

- Helppoliukoisen fosforin pitoisuus maassa suunnittelukauden alussa on 7,8 mg/l. Taso vastaa Ctukialueen vuokrapeltojen helppoliukoisen fosforin tasoa (Myyrä ym. 2003).

- Maan fosforitilan vaikutus satoon ja fosforilannoituksen vaikutus satoon maan fosforitilan suhteen on saatu MTT:n pitkäaikaisten kokeiden tuloksista (Saarela ym. 1995). Maan helppoliukoisen fosforin tason vaikutusta satoon on tarkasteltu Saarelan aineiston perusteella (taulukko 11, s. 66, suhteellinen sato $100=3500 \mathrm{~kg} / \mathrm{ha}$ ) käyttäen yhteyden kuvaamiseen Mitscherlich funktiomuotoa (Myyrä ym. 2003). 
(1) $y_{t}=3367\left(1-0,74 \exp ^{-0,37 x_{t}}\right)$

missä, $\quad \mathrm{y}_{\mathrm{t}}=$ sato

$\mathrm{x}_{\mathrm{t}}=$ maan fosforitila, helppoliukoista fosforia $(\mathrm{mg} / \mathrm{l})$

$\mathrm{e}=$ luonnollinen luku

- Saarela ym. (1995) ovat kuvanneet fosforilannoituksen suoraa vaikutusta satoon toisen asteen polynomilla. Heidän estimoimaansa funktiota käytetään sellaisenaan (2).

(2) $\Delta y_{t}=5,85+\left(21,7 u_{t}^{\frac{1}{2}}\right)-\left(0,414 x_{t} u_{t}^{\frac{1}{2}}\right)-\left(0,173 \frac{u_{t}^{2}}{x_{t}} k\right)+\left(16,2 \frac{u_{t}}{x_{t}} k\right)$

missä, $\quad \mathrm{x}_{\mathrm{t}}=$ maan helppoliukoinen fosfori $(\mathrm{mg} / \mathrm{l})$

$\mathrm{u}_{\mathrm{t}}=$ P-lannoitus $(\mathrm{kg} / \mathrm{ha})$

$\mathrm{k}=$ kasvikerroin (ohralla 1,05)

- Yksi lannoitefosforikilo nostaa maan fosforilukua $0,01 \mathrm{mg} / 1 .{ }^{1}$ Myöhemmin käytettävä parametri $\left(b_{2}\right)$.

- Vuotuisen maan helppoliukoisen fosforivarannon kuluminen kuvataan tasaprosenttipoistolla. Fosforivarannon oletetaan pienenevän ohranviljelyssä aina $2 \%$ vuodessa $\left(b_{1}\right)$. Kokeissa on kuitenkin havaittu fosforivarannon alenemassa suuria vuotuisia vaihteluita, joten tehty oletus on karkea yleistys (Yli-Halla 1989).

Lannoitefosforin vaikutusta maassa olevaan helppoliukoiseen fosforiin ei ole tarkasteltu tässä tutkimuksessa perinteisellä lannoituksen ja sadon välisellä fosforitaseella. Mallinnuksessa käytetyt oletukset summautuvat kuitenkin niin, että ympäristötuen perustason mukainen fosforilannoitus $(15 \mathrm{~kg} / \mathrm{ha})$ pitää maan helppoliukoisen fosforin määrän multavalla savimaalla tyydyttävässä viljavuusluokassa. Koko maan tasolla tehdyt havainnot tukevat oletusten paikkansapitävyyttä (Mäntylahti 2002).

Numeerisesti ratkaistavassa esimerkissä keskitytään tarkastelemaan pellonvuokraukseen liittyvän pellon hallintaoikeuden epävarmuuden vaikutusta lannoituspäätökseen. Esimerkkilaskelman lähtökohdat ovat seuraavat: Vuokraviljelijä viljelee peltoa viiden vuoden vuokrasopimuksella. Vuokrasopimus on juuri vahvistettu ja pellon hallintaoikeuteen ei siten liity epävarmuutta viiden seuraavan vuoden aikana. Vuokraviljelijä aikoo jatkaa tuotantoa vielä seuraavat 25 vuotta. Hän olisi halukas uusimaan myös nyt tarkastelun kohteena olevan pellon vuokrasopimuksen sen umpeutuessa viiden vuoden kuluttua. Vuokrasopimuksen uusiminen ei ole kuitenkaan varmaa. Seuraavat vuokrasopimukset uusiutuvatkin todennäköisyydellä 1- $\mathrm{P}_{-}$ex, eli todennäköisyydellä 1 - (vuokrasopimus ei uusiudu). Vuokraviljelijän ongelmaksi muodostuukin valita taloudellisin fosforilannoitus huomioiden fosforilannoituksen jälkivaikutus. Ongelmalliseksi tilanteen tekee viljelijän epävarmuus siitä, pääseekö hän hyödyntämään jälkivaikutusta. Ratkaisua helpottaa se, ettei maassa olevan helppoliukoisen fosforin määrän alenemasta rankaista vuokrasopimuksen lopussa.

Ongelma voidaan pilkkoa vuotuisiksi päätöksenteko-ongelmiksi, jotka voidaan ratkaista yksi kerrallaan ns. Bellmannin yhtälönä:

$$
V_{t}\left(x_{t}\right)=\max _{u_{t}}\left[p_{t}^{y} y\left(x_{t}, u_{t}\right)-p_{t}^{f} u_{t}+\beta\left(1-P_{-} e x\right) V_{t+1}\left(x_{t+1}\right)\right]
$$

missä $\mathrm{V}_{\mathrm{t}}\left(\mathrm{x}_{\mathrm{t}}\right)$ on kasvien käytössä olleen ravinnevarannon nykyarvo, kun ravinteiden käyttö on ollut optimaalista periodeilla $\mathrm{t} \rightarrow \mathrm{T}$,

\footnotetext{
${ }^{1}$ Henkilökohtainen tiedonanto. Into Saarela 27.11.2002.
} 
missä:

$\mathrm{y}\left(\mathrm{x}_{\mathrm{t}}\right)=$ ravinnevarannon satoresponssi

$\mathrm{t}=1, \ldots, 25$

$\mathrm{y}\left(\mathrm{u}_{\mathrm{t}}\right)=$ lannoitteen satoresponssi

$\mathrm{u}_{\mathrm{t}} \geq 0$ (lannoitteen käyttömäärä ei voi olla negatiivinen)

$\mathrm{P}^{\mathrm{y}}=$ sadon $\operatorname{arvo}(110 € /$ tonni $)$

$\mathrm{x}_{\mathrm{t}}=\mathrm{b}_{1}\left(\mathrm{x}_{\mathrm{t}-1}\right)+\mathrm{b}_{2}\left(\mathrm{u}_{\mathrm{t}-1}\right) \mathrm{ja}_{1}$ on annettu $(7,8 \mathrm{mg} / \mathrm{l})$

$\mathrm{P}^{\mathrm{f}}=$ fosforin hinta $(1220 € /$ tonni $)$

$\beta=$ pääomitusparametri laskentakorko $5 \%, \mathrm{~V}_{26}\left\{\mathrm{X}_{26}\right\}=0$

P_ex= todennäköisyys, jolla vuokrasopimus ei uusiudu.

Ravinnevarannon nykyarvon maksimointiongelman (3) ensimmäisen kertaluvun ehto voidaan kirjoittaa: Periodilla t käytetyn lannoitekilon arvo on sama kuin sen periodeilla t...T aikaansaaman sadon nykyarvo eli niiden erotus on nolla. Epävarmuus kytkeytyy tähän siten, ettei tiedetä, kuinka pitkään nyt käytetyn fosforilannoituskilon jälkivaikutuksesta päästään nauttimaan. Mallilaskelmassa kokeillaan erilaisia todennäköisyyksiä sille, etteivät vuokrasopimukset uusiudu (P_ex: $0 \ldots 0,2 \ldots 0,8$ ja 1$)$. P_ex $=0$ tarkoittaa sitä, että vuokrasopimus uusiutuu varmasti. Tilanne vastaa omistajaviljelijän suorittamaa viljelyä, jossa pellon hallintaan ei liity epävarmuutta.

\section{Tulokset ja tulosten tarkastelu}

Lannoitusta koskevilla analyyseillä tarkastellaan yleensä tuotteiden ja panosten hintojen ja niiden muutosten vaikutusta taloudelliseen lannoitukseen. Tässä artikkelissa ei tarkastella hintamuutosten vaikutuksia eikä tehdä herkkyysanalyysiä käytettävän lannoituksen responssifunktion funktiomuodon vaikutuksesta (Bäckman 1997, Sumelius 1993). Edellä mainittuja herkkyysanalyysejä on aikaisemmin raportoitu MTT:n selvityksiä sarjassa (Myyrä ym. 2003). On myös huomattava, että esitettävät ratkaisut pätevät tarkastelun kohteena olevan vuokrapellon fosforiluokan ollessa "tyydyttävä". Ratkaisut muuttuvat olennaisesti, jos fosforiluokka on jokin muu.

Tulosten perusteella vuokraviljelijän odotukset vuokrasopimuksen jatkumisesta vaikuttavat olennaisesti taloudellisesti perusteltavaan fosforilannoitukseen. Oletettaessa vuokrasopimuksen jatkuvan varmasti on lannoitus lähellä omistajaviljelijän lannoitusta, joka käytetyillä hintatasoilla oli noin $17 \mathrm{~kg} / \mathrm{ha}$. Vaikka 25 vuoden suunnittelujaksoa voidaan pitää melko pitkänä, vaikuttaa tietoisuus suunnittelukauden loppumisesta kuitenkin siis jo tässä vaiheessa. Kun vuokrasopimusten uusiutumiseen liittyvää epävarmuutta lisätään, alenee taloudellinen fosforilannoitus nopeasti (kuva 1). Pellon hallintaoikeuden epävarmentuessa pellon sadontuottokykyyn ei kannata panostaa samalla tavalla kuin omistuksessa olevien peltojen kasvukuntoon. Hallintaoikeuden epävarmuuden vaikutus ei ole kuitenkaan lineaarinen. Pienikin epävarmuus pellon hallintaoikeuden jatkumisesta alentaa heti taloudellista fosforilannoitusta. Esimerkkilaskelmassa $20 \%$ riski menettää vuokrasopimus viiden vuoden päästä alentaa taloudellisen fosforilannoituksen alle $12 \mathrm{~kg}: \mathrm{oon} / \mathrm{ha}$.

Tulosten perusteella havaitaan myös, että varmasti jäljellä olevan hallintaoikeuden pituus vaikuttaa olennaisesti taloudelliseen fosforilannoitukseen (kuva 1). Vuokrasopimuksen uusiutumisen epävarmuuden ollessa $60 \%$ voimassa olevan vuokrasopimuksen ensimmäisenä vuonna fosforia kannattaa käyttää n. $10 \mathrm{~kg} / \mathrm{ha}$ ja viimeisenä vuonna n. $6 \mathrm{~kg} / \mathrm{ha}$. 


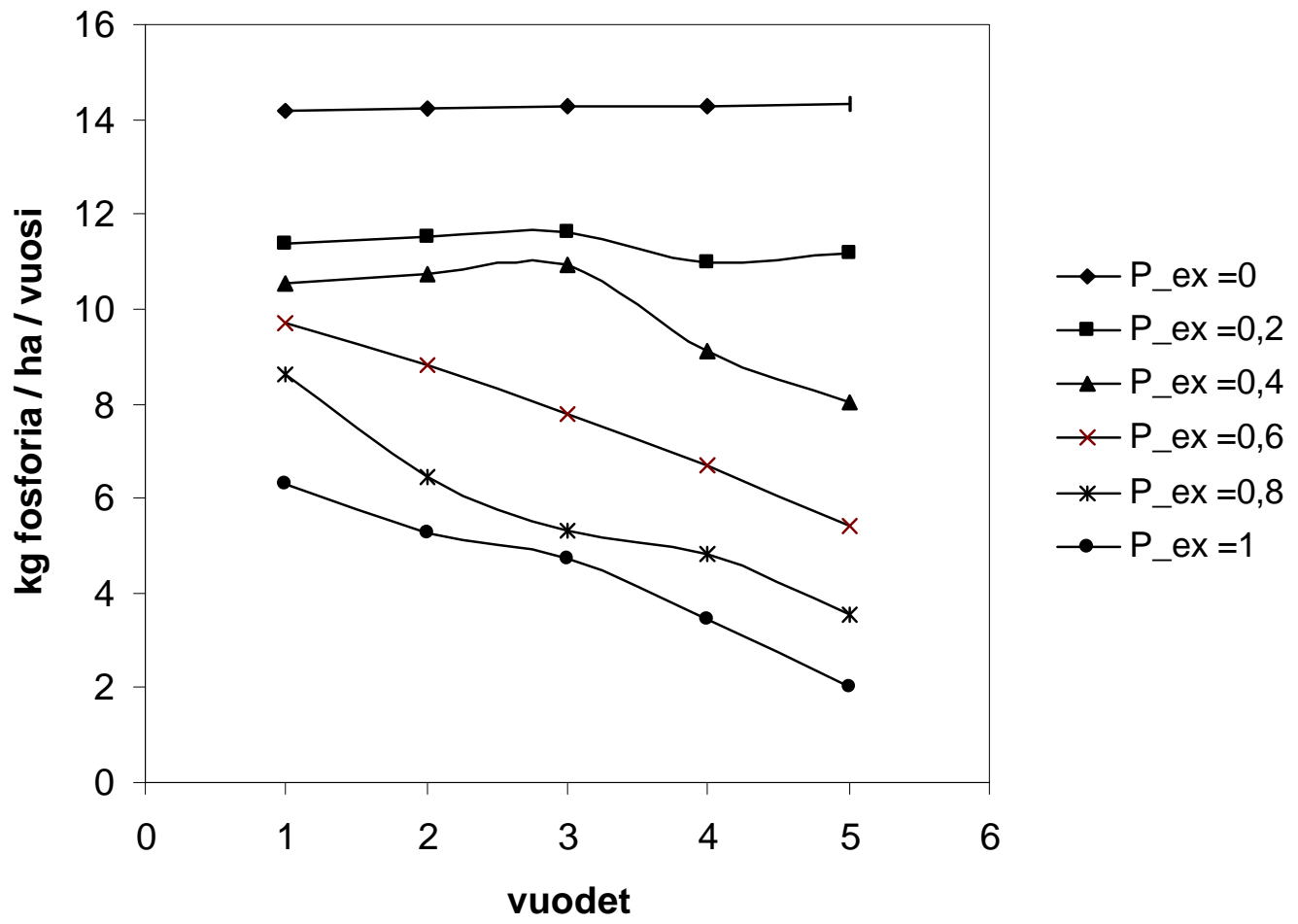

Kuva 1. Taloudellinen fosforilannoitus 25 vuoden suunnittelujakson viitenä ensimmäisenä vuonna, kun 5 vuoden jaksoissa uusiutuvan vuokrasopimuksen uusiutumistodennäköisyys vaihtelee. Maassa olevan helppoliukoisen fosforin määrä on kaikissa tapauksissa ensimmäisenä vuonna sama $(7,8$ mg/l).

\section{Johtopäätökset}

Vuokraviljelmän fosforilannoitussuunnitelmaa tehtäessä vuokrasopimuksen pituus ja sen uusiutumisen todennäköisyys ovat maassa olevan helppoliukoisen fosforin ohella keskeisimpiä taloudelliseen fosforilannoitukseen vaikuttavia tekijöitä. Lyhyillä ja epävarmasti uusiutuvilla vuokrasopimuksilla toimittaessa taloudellisesti kannattava fosforilannoitus poikkeaa merkittävästi omille pelloille tehtävästä fosforilannoituksesta, helppoliukoisen fosforin ollessa viljavuusluokassa tyydyttävä.

Suunnitteluun vaikuttavissa muissa taloudellisissa tekijöissä tapahtuvat muutokset eivät poista suunnittelujänteen lyhenemisen ja epävarmuuden fosforilannoitteen käytön alentamiseen kannustavaa vaikutusta. Tämä voi pitkällä aikavälillä johtaa vuokraviljeltyjen peltojen sadontuottokyvyn ja tuottavuuden alenemiseen.

Bäckman, S.T., Vermeulen, S. \& Taavitsainen, V-M. 1997. Long term fertilizer field trials: comparison of three mathematical response models. Agricultural and Food Science in Finland 6(2): 151-160.

Kennedy, J. 1986. Dynamic programming. Applications to agriculture and natural resources. Australia. $341 \mathrm{s.}$

Maataloustilastollinen vuosikirja 2002. Maa-ja metsätalousministeriön tietopalvelukeskus.

Myyrä, S., Ketoja, E. \& Yli-Halla, M. 2003. Pellon hallintaoikeuden yhteys maanparannuksiin - esimerkkinä kalkitus ja fosforilannoitus. MTT:n selvityksiä 37. 51 s., 4 liitettä.

Mäntylahti, V. 2002. Peltojen ravinnetilan kehitys 50 vuoden aikana. Teoksessa: Uusitalo, R. (toim.) \& Salo, R. (toim.). Tutkittu maa - turvalliset elintarvikkeet. Maa- ja elintarviketalous 13: 5-13. ISBN 951-729-694-0.

Saarela, I., Järvi, A., Hakkola, H., \& Rinne, K. 1995. Fosforilannoituksen porraskokeet 1977-1994. Vuosittain annetun fosforimäärän vaikutus maan viljavuuteen ja peltokasvien satoon monivuotisissa kenttäkokeissa. Maatalouden tutkimuskeskuksen tiedote 16/95. ISSN 0359-7652. 94 s. + 14 liitettä.

Sumelius, J. 1993. A response analysis of wheat and barley to nitrogen in Finland. Agricultural Science in Finland 2(6):465-479.

Yli-Halla, M. 1989. Effect of different rates of $\mathrm{P}$ fertilization on the yield and $\mathrm{P}$ status of the soil in two longterm field experiements. Journal of agricultural science in Finland 61:361-370. 